\title{
Production capacity of metallurgical enterprises in modular structure of management accounting
}

\author{
E.S. Zambrzhitskaia ${ }^{1,{ }^{*}}$, D.G. Neshporenko ${ }^{1}$, and O.V. Dolgopolov ${ }^{1}$ \\ ${ }^{1}$ Nosov Magnitogorsk State Technical University (NMSTU), Lenin Street, 38, Magnitogorsk city, Chelyabinsk Region, Russia
}

\begin{abstract}
This article is the result of constant research in development of management accounting at modern Russian metallurgical works. The required steps of renovation are presented for the modernization of management accounting system in the case of production capacity. The necessary factors with defined values are systematized for modern enterprises. The main ones are those which are regulate the measure of the payload of production capacity. For the purposes of effective management accounting at metallurgical enterprises it is suggested to use the system of controlling parameters which were formulated for the enterprise for production of rolls. Later in the article the necessary changes to the modular structure of management accounting business are described and expanded with new structural element - "Management of production capacity". The suggested methodical approach will allow the company management to respond quickly to rapidly changing external environment and, as a consequence, to make effective management decisions.
\end{abstract}

\section{Introduction}

The economic policy of any state is aimed for such purposes and scales, that the gross domestic product was more optimal.

Gross domestic product is a macroeconomic indicator that reflects the market value of all final goods and services (that is aimed for direct consumption) produced per year in all sectors of the economy in the State for consumption, exports and savings [1].

It is important to note that the solution of any macroeconomic problem is better to start with each individual company, its divisions and jobs. The maximum possible output of the production units of the enterprise production for a given period is determined by the index of industrial output (production capacity) [2].

It should be noted that in modern conditions of managing, the production capacity as the micro-level indicator (PM) have been neglected. Most economists practitioners believe that the figure static, unchanged over time. In other words, it is assumed that the value of the production capacity is determined at the design stage of the production system and is independent of external and internal factors affecting the continued operation of the enterprise.

Meanwhile, in the scientific and specialized literature, there are well-established view that the efficiency of use of production capacity depends on a number of factors associated with the presence and the real possibilities of maneuver available to the enterprises manufacturing resources - means of labor, objects of labor, human labor, professional management, etc [3, 4].
It is important to note that the calculation of the production capacity of the structural units of the enterprise issue is more technical and technological. At the same time, the question of efficiency of use of production capacities and interfaces of structural units in the same industrial complex has distinct economic aspects $[5,6,7]$.

\section{Problem Statement}

The existing theories of planning the production capacity follow the idea of factors, influencing the value of PC ( production capacity), which are $[8,9,10]$ :

1) factors for organization of production processes (level of equipment maintenance, regularity and rhythm of production, utilization of production space, the degree of use of the equipment);

2) factors of labor potential (training and skills development, motivation to improve equipment utilization, development of creative potential of employees, progressive forms of work organization);

3) factors of technical and technological issues (the perfection of machinery equipment, technology products, equipment downtime for repairs, advanced technology, cooperation in the production);

4) factors of the organization and management of production (outstaffing, logistic service production, focusing production capacity).

Three-dimensional factor model E.V. Novikov allows you to select over thirty key factors [11]. The variety of conditions (factors), improving production capacity and the extent of its use make the mathematical modeling of the process indicator too sophisticated. 
For these purposes, E.V. Novikov suggested to select the components of the direct interaction of (baseline factors) and dependent, derived from the basic factors.

As the basic factors taken following - the demand for products and performance that defines the capabilities of the enterprise to meet the market demand.

The model of economic growth by A.M. Fattakhova describes the production capacity as a dependence on the industrial, economic and financial activity of the economic entity, which in turn provides a stable activity of the company, which is building some good, satisfying the needs of the market and retaining competitive advantage $[12,13]$.

The presented analysis of the factors affecting the value of the index of production capacity, allows us to conclude that the production capacity is a reflection of "resultant" of all used production and management factors on the particular enterprise.

\section{Main Part}

\subsection{Analysis of the structure of the production system of metal-working enterprises}

The issue of management of production capacity is significant for all sectors of the economy, but it acquires a special urgency for metalworking companies where the production process is asset-intensive and multi-layered.

For management purposes, the production capacity is proposed to define the controlled parameters. The value of these parameters should allow to assess the production capacity of the value sensitivity to changes in the internal and external environment of the enterprise.

It is mandatory to be specifically developed a clear and relatively simple methodology for quantitative (numerical) assessment of efficiency of production capacity, which allows for specific managerial situations to determine the ratio of its value at low labor costs (man-hours).

The effect of controlled process of this indicator will depend directly on the degree of objectivity, reliability, progressiveness of the selected parameter.

Let us consider the proposed methodological approach on a concrete example of a metalworking enterprise, which produces the following kinds of production:

1) increased accuracy shaft;

2) spline grooves shaft;

3) whittled grooves shaft.

The entire manufacturing process is carried out at six production sites.

The production site No. 1 is a stamping shop. The stamping is a process of plastic deformation of the material with changes in body shape and size. The presses used for the process of stamping are devices to deform the material by means of mechanical influence.

For giving the product a certain shape is used at the factory shaft stamping.

The shaft stamping is an operation of metal forming, and obtainment of axisymmetric parts of the cylindrical workpiece by the simultaneous action of the radial and axial loads. An axial load of the workpiece is generated due to the movement of the punch, the radial load is generated through the running of its lateral surface in the rollers or shafts. Thus, the shaft stamping is a way for the complex local deformation, in which in a single technological process takes place a combination of one of the basic forging operations, specifically firmware or precipitation with transversal rolling or running.

The shaft stamping improves the physical and mechanical properties of processed metal, ensuring the required arrangement of its fibres, which improves operational properties of the resulting parts.

The production site No. 2 is a turning shop. The turning is a cutting machining of external and internal surfaces of rotation, including a cylindrical and conical, trimming, cutting, chamfering, processing fillets, slotting, cutting internal and external threads on lathes.

The production site No. 3 is a thermochemical treatment. The thermochemical treatment is a heating and holding of materials at high temperatures in reactive environments (solid, liquid, gaseous).

The thermochemical treatment is carried out with the purpose of enrichment of the surface layers of products of certain elements. They are named by specialists "the saturating elements" or "the components of the saturation". As a result of thermochemical treatment is formed the diffusion layer, namely changes the chemical composition, phase composition, structure and properties of surface layers. The change in chemical composition causes changes in the structure and properties of the diffusion layer.

The production site No. 4 is a planer shop. The planing is a machining process of materials by cutting by chip removal, carried out by the relative reciprocating movement of the tool or product. For the metal planing treatment there are used the different machines: transverse- and longitudinal-planing, hem-planing, planing-slotting machines and the others.

The production site No. 5 is a milling shop. The milling is a mechanic machining process in which the cutting tool (mill) performs a rotational movement, and the workpiece makes a forward movement.

The production site No. 6 is a grinding shop. The grinding is a mechanical or a manual operation on the metal processing. It's a variety of the abrasive treatment, which, in turn, is a type of cutting. The mechanical grinding is usually used to a processing of metals to specified size with micron precision, as well as to achieve the smallest surface roughness of the product acceptable valid the GOST (State Standard).

To obtain the increased accuracy shaft it is necessary the workpiece passed the following production areas: punching $\rightarrow$ heat treatment $\rightarrow$ turning $\rightarrow$ planing.

To obtain the spline grooves shaft it is necessary the workpiece passed the following production areas: punching $\rightarrow$ turning $\rightarrow$ heat treatment $\rightarrow$ milling.

To obtain the whittling grooves shaft it is necessary the workpiece passed the following production areas: punching $\rightarrow$ turning $\rightarrow$ heat treatment $\rightarrow$ grinding.

Taking into account the peculiarities of the technological process described above, the company operates a network of the technological interactions, 
which is presented in a graph form in fig. $1[14,15]$. The circles mean the kinds of products, the arrow shows the expenditure of some kinds of products on the production of others. The rectangles indicate the links of the production system.

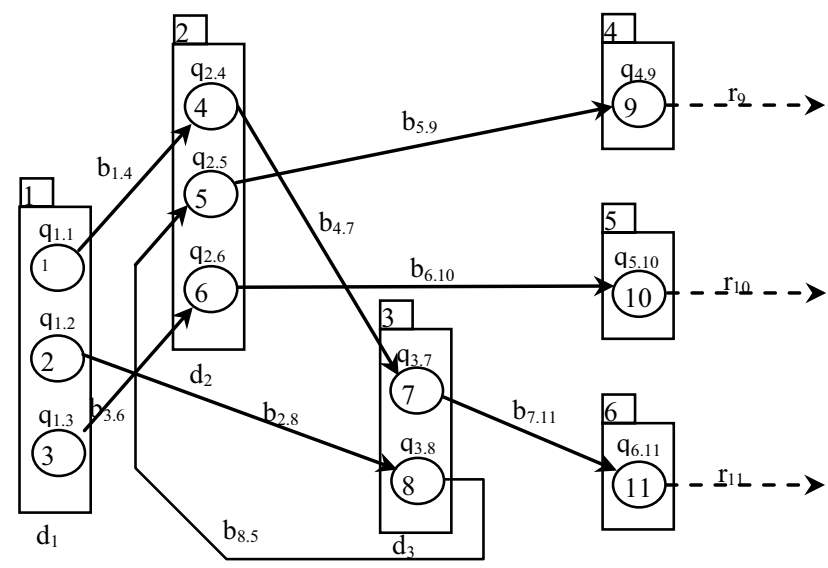

Fig. 1. The structure of the production system (metal working factory). In fig. 1 are the following notation: $\mathrm{q}$ - the production capacity of the links on the products; $b$ - the coefficients for direct costs of the products on the products; $r$ - the product range structure of the final production.

Thus, the considered example shows us modern metal working factories present themselves as a comprehensive multi-stage system, an important indicator of which is the amount of the production capacity and the efficiency of their use.

\subsection{Determining the system of controlled parameters}

In the aim of the organization of management accounting of production capacities at the studied enterprise can be offered as the monitored parameters the following indicators [16 - 20]:

- an availability of integrated information (automated) system of management accounting, monitoring and control of industrial capacity and the level of its use;

- the diagnostics of the organizational and technical level of the main shops at the industrial enterprise;

- an assessment of the manufacturing opportunities regarding the labour expenses, natural and monetary terms on the problems decision of modernization, reconstruction and technical re-equipment at the enterprise;

- analysis of uneven production load jobs, of imbalance of the capacities of the production facilities and productive capacity of the structural subdivisions;

- the identification of free capacities, of reserves and bottlenecks in the production;

- the self-cost per unit of production;

- the indicators of the labour productivity (the indices of labor productivity associated with number of personnel, the actual value of revenue generated);

- the value of the differential costs of the operation production capacities of the enterprise by autonomous business units taking into account the market conditions;
- the assortment structure of finished production and its compliance with the market conditions (the structure of production capacity to market demand); etc.

\subsection{The results of the study}

After the systematizing the proposed control options it may be possible to allocate the main management capacity element of metal working production of the enterprise. It may be the creation of the automated unit of information automatic base of management accounting, monitoring and control of industrial capacity and of the level of its use.

According to the modular structure of the management accounting proposed by $O$. Kaverina currently, there are three segment of management: budgeting and monitoring of the execution of budgets, calculation of the cost of production and the special managerial decisions shown in Fig. 2.a [21].

According to the authors, it is reasonable in this model to make an additional segment which is responsible for control of the value production capacity at the business entity presented in Fig. 2.b.

\begin{tabular}{|c|c|}
\hline $\begin{array}{c}\text { Budgeting and } \\
\text { monitoring } \\
\text { execution of budgets }\end{array}$ & $\begin{array}{c}\text { Calculation of the } \\
\text { product cost and the } \\
\text { processes cost }\end{array}$ \\
\hline $\begin{array}{c}\text { Special management } \\
\text { decisions }\end{array}$ & \multicolumn{1}{|c}{} \\
\hline
\end{tabular}

a)

\begin{tabular}{|c|c|}
\hline $\begin{array}{c}\text { Budgeting and } \\
\text { monitoring } \\
\text { execution of the budgets }\end{array}$ & $\begin{array}{c}\text { Calculation of the product } \\
\text { cost and the processes cost }\end{array}$ \\
\hline $\begin{array}{c}\text { Special management } \\
\text { decisions }\end{array}$ & $\begin{array}{c}\text { The production capacity of } \\
\text { an enterprise and structural } \\
\text { unit }\end{array}$ \\
\hline
\end{tabular}

Fig. 2. The modular structure of management accounting by the method of $\mathrm{O}$. Kaverina before change (a) and after change (b).

\section{Conclusion}

The lack of management accounting of production capacity and the level of their use suggests that still may be not resolve an independent task by the objective assessment of the indicators of production capacity of industries with the complex technological cycle, in terms of conjugate objects.

In conclusion, it should be noted the proposed methodological solutions for improving the efficiency of the use of production capacity can be used not only on metal working production but also in other sectors of economics.

The main conditions of the effective administrative decisions are:

1) the creation of the module "Management of manufacturing capacity" in the structure of management accounting at the enterprise;

2) detailed study of the system-controlled parameters of the effective use of production capacity, in the 
conditions of dynamically changing external environment.

\section{References}

1. T.Yu. Matveyeva, An introduction to the Macroeconomics: textbook (HSE Publishing House, Moscow, 2010)

2. E.M. Korotkov, I.Yu. Soldatova, The foundation of Management: textbook, Publishing \& Trading Corporation (Dashkov and Ko, Moscow, 2013)

3. E.S. Zambrzhitskaya, A.V. Logacheva, M.V. Logacheva, Young scientist, 10(69), 238-242 (2014)

4. M.I. Tertyshnik, I.A. Dmitrieva (Ageeva), Economy of Russia and its regions: issues of efficiency and development strategy, 241-246 (2005)

5. N.I. Gavrilenko, R.P. Kuksin, O.V. Baguzova, Vestnik of IIEL, 4(5), 58-60 (2011)

6. K.S. Krivyakin, Journal of VSTU, 2, 36-39 (2010)

7. S.N. Tsimbalyuk, T.V. Kozlova, Actual problems of modern science, technology and education, 2, 280-284 (2010)

8. G.I. Shepelenko, The production planning at the enterprise. Economics and management: textbook for students of economics (Publishing Centre «March», Rostov-on-Don, 2004)

9. M.V. Dadalova, Journal of the university of cooperation, Economics and Law, 4, 290-294 (2008)

10. V.S. Tikhonov, M.A. Brajnikov, Higher education, business, enterprise, 1st ed. high school collection of scientific papers, 116-120 (2003)
11. E.V. Novikov, Journal of South-Russian State Technical University. Series of sociology and economics, 1, 71-74 (2012)

12. A.M. Fattakhov, Using production capacity and strategic stability of the oil refining enterprises (Ufa, 2005)

13. G.V. Danilov, I.G. Ryzhova, E.S. Voynova, Economy analysis: the theory and practice, 3(168), 34-39 (2010)

14. G.V. Danilov, I.G. Ryzhova, E.S. Voynova, St. Petersburg State Polytechnical University Journal. Economics, 4(102), 87-90 (2010)

15. V.N. Kononov, I.G. Ryzhova, E.S. Voynova, Topical issues of economic science, 12-2, 167 176 (2010)

16. R. Zeman, M. Vochozka, E.S. Zambrzhitskaya, N.E. Ivanova, R. Píchová, M. Popílková, K. Kabourková, Management accounting: textbook for high schools education (Magnitogorsk, 2015)

17. V.T. Chaya, N.I. Chupahina, Management accounting: a textbook and a workshop for the academic bachelor (Moscow, Publisher House YURAYT, 2016)

18. G.Ya. Ostayev, Management accounting: a textbook (Business and Service, Moscow, 2015)

19. O.E. Nikolayeva, T. Shishkova, Classic management accounting: a textbook (Krasand, Moscow, 2014)

20. E.S. Zambrzhitskaya, Remote course Management accounting: e-training complex, Chronicles of the combined fund of electronic resources: Science and Education, 11(78), (2015)

21. O.D. Kaverina, Management accounting: theory and practice: textbook for students (Publisher House YURAYT, Moscow, 2014) 